\title{
Genetic parameters for body weight from birth to calving and associations between weights with test-day, health, and female fertility traits
}

\author{
Tong Yin and Sven König ${ }^{1}$ \\ Institute of Animal Breeding and Genetics, Justus-Liebig-University Gießen, 35390 Gießen, Germany
}

\begin{abstract}
A data set including 57,868 records for calf birth weight $(\mathrm{CABW})$ and 9,462 records for weight at first insemination (IBW) were used for the estimation of direct and maternal genetic effects in Holstein Friesian dairy cattle. Furthermore, CABW and IBW were correlated with test-day production records and health traits in first-lactation cows, and with nonreturn rates in heifers. Health traits considered overall disease categories from the International Committee for Animal Recording diagnosis key, including the general disease status, diarrhea, respiratory diseases, mastitis, claw disorders, female fertility disorders, and metabolic disorders. For single-trait measurements of CABW and IBW, animal models with maternal genetic effects were applied. The direct heritability was 0.47 for CABW and 0.20 for IBW, and the direct genetic correlation between $\mathrm{CABW}$ and IBW was 0.31 . A moderate maternal heritability (0.19) was identified for CABW, but the maternal genetic effect was close to zero for IBW. The correlation between direct and maternal genetic effects was antagonistic for CABW (-0.39) and for IBW (-0.24). In bivariate animal models, only weak genetic and phenotypic correlations were identified between CABW and IBW with either test-day production or health traits in early lactation. Apart from metabolic disorders, there was a general tendency for increasing disease susceptibilities with increasing $\mathrm{CABW}$. The genetic correlation between IBW and nonreturn rates in heifers after 56 $\mathrm{d}$ and after $90 \mathrm{~d}$ was slightly positive (0.18), but close to zero when correlating nonreturn rates with $\mathrm{CABW}$. For the longitudinal BW structure from birth to the age of $24 \mathrm{mo}$, random regression models with the timedependent covariate "age in months" were applied. Evaluation criteria (Bayesian information criterion and residual variances) suggested Legendre polynomials of order 3 to modeling the longitudinal body weight (BW) structure. Direct heritabilities around birth and insemination dates were slightly larger than estimates
\end{abstract}

Received September 14, 2017.

Accepted November 1, 2017.

${ }^{1}$ Corresponding author: sven.koenig@agrar.uni-giessen.de for $\mathrm{CABW}$ and IBW from the single-trait models, but maternal heritabilities were exactly the same from both models. Genetic correlations between BW were close to 1 for neighboring age classes, but decreased with increasing time spans. The genetic correlation between BW at d 0 (birth date) and at 24 mo was even negative $(-0.20)$. Random regression model estimates confirmed the antagonistic relationship between direct and maternal genetic effects, especially during calfhood. This study based on a large data set in dairy cattle confirmed genetic parameters and (co)variance components for BW as identified in beef cattle populations. However, BW records from an early stage of life were inappropriate early predictors for dairy cow health and productivity.

Key words: body weight, health and fertility trait, genetic parameter

\section{INTRODUCTION}

Body weight of dairy cattle is a novel trait of increasing economic importance, because BW change indicates maintenance requirements of lactating cows and growing heifers, determines the carcass values of cows, and is associated with weight development in offspring (Byrne et al., 2016). Energy balance modeling via BW changes is also important from a breeding perspective, especially during the early lactation stage directly after calving (Coffey et al., 2002). The negative energy balance impairs health and fertility (Collard et al., 2000), as well as productivity in the ongoing and later lactations of milking cows (Berry et al., 2003a). Compared with other components determining energy balance (e.g., DMI, methane emissions, or $\mathrm{NE}_{\mathrm{M}}$ ), BW is quite easy to measure under practical on-farm conditions.

Direct heritabilities for BW from different age points reported in literature were in a moderate to high range (Table 1), indicating the potential for genetic improvements. Also moderate to high genetic correlations between BW of milking cows with DMI and energy balance (Veerkamp et al., 2000) suggest BW recording and utilization for correlated selection response. However, for production and reproduction traits, genetic 
correlations with BW were low and varied across studies (Table 1). For calf birth weight $(\mathbf{C A B W})$, direct heritabilities were significantly larger compared with maternal heritabilities (Everett and Magee, 1965; Johanson et al., 2011). Moderate to high positive genetic correlations between $\mathrm{CABW}$ with dystocia, perinatal mortality, and gestation length were reported by Johanson et al. (2011). Availability of producer diagnosis keys for cow health traits according to International Committee for Animal Recording (ICAR) guidelines (Stock et al., 2013), and reflecting the disease categories of claw disorders, mastitis, metabolic disorders, and female fertility disorders, allow further association studies with BW measurements. However, to our knowledge, detailed genetic analyses in this regard are lacking.

Body weight recording allows a longitudinal data structure measured at different time points, including birth weight, weaning weight, cow calving weight, or BW from different lactation stages (Lamb and Barker, 1975; Coffey et al., 2006). Generally, genetic correlations for weight measurements from time points in close distance were quite large [e.g., 0.79 between birth weight and weaning weight (Coffey et al., 2006)], and between BW in wk 1 and 15 of lactation (Veerkamp and Thompson, 1999). In contrast, genetic correlations between distant time measurements were quite small [e.g., 0.14 between BW from d 50 to 900; Brotherstone et al. (2007)]. For genetic analyses of longitudinal weight data, repeatability models (e.g., Abdallah and McDaniel, 2000), multiple trait models (e.g., Veerkamp and Thompson, 1999), or the random regression model (RRM, e.g., Coffey et al., 2006) can be applied. Repeatability model applications assume identical genetic and environmental variances across the given time period. An alternative is to consider repeated weight measurements from different periods as separate traits, being the data basis for multiple trait model applications (Veerkamp and Thompson, 1999). Multiple trait models allow consideration of altering additive-genetic and residual variances, with positive effects on the accuracy of genetic evaluations (Thompson and Meyer, 1986). However, in the case of a large number of traits, the multiple-trait model might be over-parameterized (Veerkamp and Thompson, 1999). In RRM, alterations of genetic parameters and breeding values over the recording trajectory can be estimated based on a limited number of random regression coefficients.

Table 1. Overview of heritabilities for BW traits and their genetic correlations with production, fertility, and health traits in Holstein cows

\begin{tabular}{|c|c|c|c|c|c|}
\hline Trait & \multicolumn{2}{|c|}{ Heritability } & \multicolumn{2}{|l|}{ Genetic correlation } & Reference \\
\hline Birth weight & 0.22 & 0.04 & Gestation length & 0.57 & Everett and Magee, 1965 \\
\hline \multirow{3}{*}{ Birth weight } & 0.26 & 0.08 & Dystocia & 0.73 & Johanson et al., 2011 \\
\hline & & & Perinatal mortality & 0.57 & \\
\hline & & & Gestation length & 0.52 & \\
\hline \multirow{4}{*}{$\mathrm{BW}^{1}$} & & & Interval to first service & -0.25 & \\
\hline & & & Pregnant to first service & -0.22 & \\
\hline & & & First service to conception interval & 0.37 & \\
\hline & & & Number of services & 0.15 & \\
\hline \multirow[t]{2}{*}{$\mathrm{BW}^{2}$} & 0.17 & & $3.7 \% \mathrm{FCM}$ & -0.15 & Abdallah and McDaniel, 2000 \\
\hline & & & $2 \times, 305-\mathrm{d}$, mature equivalent fat yield & -0.11 & \\
\hline Live weight $^{3}$ & 0.35 & & Fat- and protein-corrected milk & -0.10 & Lassen and Løvendahl, 2016 \\
\hline \multirow[t]{6}{*}{ Live weight ${ }^{4}$} & 0.48 & & Milk yield & -0.06 & Veerkamp et al., 2000 \\
\hline & & & Fat yield & 0.31 & \\
\hline & & & Protein yield & 0.20 & \\
\hline & & & DMI & 0.76 & \\
\hline & & & Energy balance & 0.45 & \\
\hline & & & Interval until first luteal activity & -0.11 & \\
\hline
\end{tabular}

\footnotetext{
${ }^{1}$ Average BW from DIM 5, 60, 120, 180.

${ }^{2}$ Predicted BW after calving.

${ }^{3}$ Weekly average live weight measured by automatic milking systems.

${ }^{4}$ Live weight within the first week of first-lactation cows.
} 
Apart from CABW and weaning weight, there is a gap addressing genetic investigations for weight records along the trajectory between birth and first calving. Furthermore, genetic associations between BW during aging with health and productivity are unclear. Hence, the objectives of the present study were to (1) estimate genetic parameters for CABW and body weight at first insemination (IBW) applying multiple trait models, (2) to infer genetic and phenotypic relationships between CABW and IBW with nonreturn rates in heifers, and with production and health traits during the early lactation period of first-parity cows, and (3) to analyze longitudinal BW records from birth to first calving applying RRM.

\section{MATERIALS AND METHODS}

\section{Data}

$\boldsymbol{C A} \boldsymbol{B} \boldsymbol{W}$ and $\boldsymbol{I} \boldsymbol{B} \boldsymbol{W}$. The $\mathrm{CABW}$ was available from 57,868 animals kept in 53 large-scale contract herds located in 2 federal states of northeast Germany. The calves were born from 2005 to 2014, and CABW varied between 20 to $60 \mathrm{~kg}$. No further outliers for CABW were detected. A subset of 9,462 heifers additionally had records for IBW. Heifers with IBW were extracted according to their weight date and first insemination date. If the difference between the 2 dates was shorter than $10 \mathrm{~d}$, the heifer weight was considered as IBW. Insemination age of the 9,462 heifers varied from 329 to $777 \mathrm{~d}$, with an average value of $452.68 \mathrm{~d}$. On average, the difference between weight date and first insemination date was $5.05 \mathrm{~d}$.

Cow Production and Health Traits. Production and health traits were available from first-lactation cows. Analogous to Mahmoud et al. (2017), the production traits included records from the first and second official test-day after calving for milk yield (MY1 and MY2), fat percentage (FP1 and FP2), protein percentage (PP1 and PP2), fat yield (FY1 and FY2), protein yield (PY1 and PY2), fat to protein ratio (FPR1 and FPR2), and SCS (SCS1 and SCS2).

Health traits of first-lactation cows were recorded according to the hierarchical diagnosis key as considered in the official ICAR guidelines (Stock et al., 2013). For the present analyses, the same overall disease categories as introduced by Mahmoud et al. (2017) were used. These were the general disease status (GDS), diarrhea (DIA), respiratory diseases (RD), mastitis (MAST), claw disorders (CL), female fertility disorders (FF), and metabolic disorders (MET). The overall disease trait category GDS reflects the first level of the hierarchical diagnosis key (i.e., just a classification if a cow is healthy or sick, without specifying the disease).
The remaining disease categories used in this study (RD, MAST, CL, FF, and MET) represent the second level of the diagnosis key. The diagnosis key also has options for a detailed disease specification including, for example, the location of the disease in the case of claw disorders. However, the detailed specification system for single diseases was not used in all herds, and for some specific diseases, incidences were quite low. Hence, we decided to use the diagnosis key levels 1 and 2 with the corresponding disease categories in the present study. If one entry of the particular disease category was observed in the first lactation, a value of 1 was assigned for a sick cow. Otherwise, a 0 was assigned for a healthy cow.

Heifer Fertility Traits. Female fertility traits of heifers were the nonreturn rate after $56 \mathrm{~d}$ (NRR56) and the nonreturn rate after $90 \mathrm{~d}$ (NRR90). The NRR56 and NRR90 were also defined as binary traits, with a 0 for nonpregnant heifers and a 1 for pregnant heifers. Descriptive statistics for CABW, IBW, cow production, and cow health traits, as well as reproduction traits from heifers are summarized in Tables 2 and 3.

Longitudinal Weight Data. In the selected largescale contract herds, weight recording of calves and heifers from different age stages was performed in close intervals because of automatically installed weighting technique. The $\mathrm{CABW}$ was available from all calves from the herd, and a large subset was recorded for IBW. A large fraction of animals was weighed shortly before first calving at an age of 24 mo. Hence, the time span for repeated measurement analyses was from birth to an age of 24 mo. Only animals with a record for CABW and 5 repeated measurements were considered. The effects of the herd, weighing year, and weighing month were combined to create a contemporary group "herdyear-month." Editing criterion was that each level of the herd-year-month effect included at least 10 weight records. Weight outliers were detected by studentized residuals, reflecting the influence of each weight record on the overall estimates. For each weight record, studentized residuals and corresponding Bonferroni $P$ values were calculated using the outlier test function in the R-package "car" (Fox and Weisberg, 2011). Records with $P$-value smaller than 0.05 or larger than 0.95 were excluded as outliers. Finally, 32,404 longitudinal weight observations from 4,952 animals were considered.

\section{Statistical Models}

Single Weight Measurement Analysis: Genetic Parameters for $C A B W$ and $I B W$. An animal model with maternal genetic effects was applied to estimate genetic (co)variance components for CABW and IBW. 
Table 2. Descriptive statistics for calf birth weight, weight at first insemination, weight from 0 to 24 mo, and test-day production traits

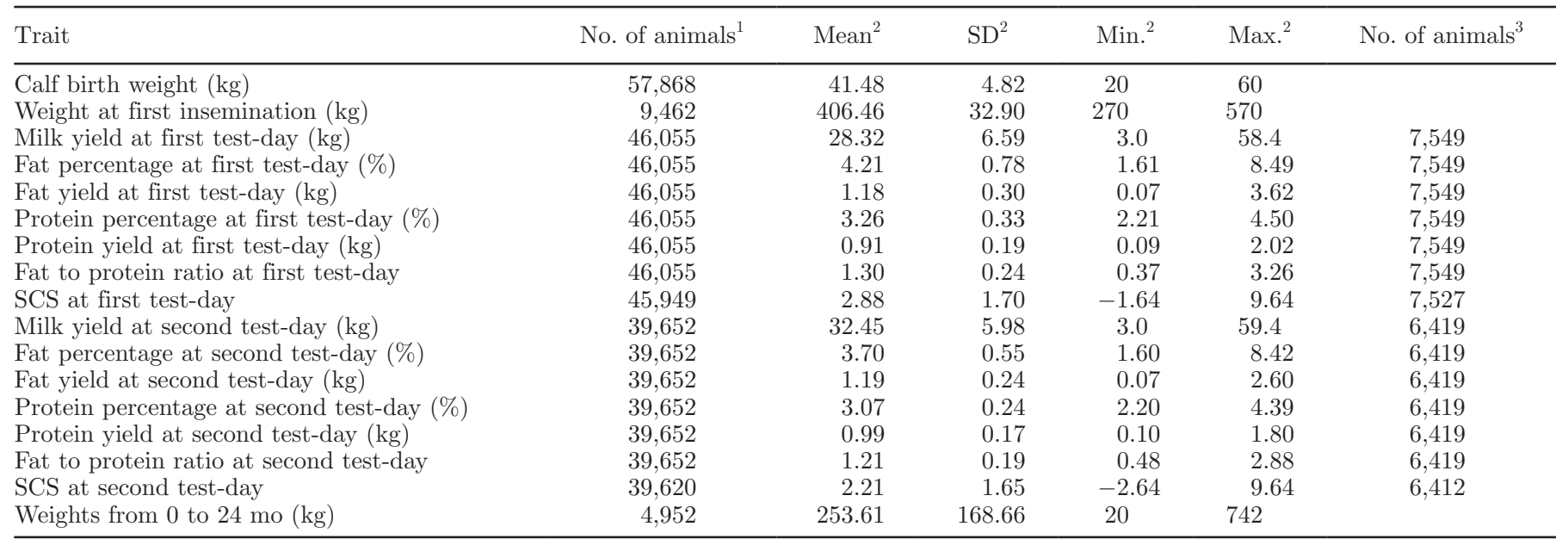

${ }^{1}$ No. of animals for estimating genetic correlations between calf birth weight and test-day, health, and fertility traits.

${ }^{2}$ Mean, SD, minimum (Min.), and maximum (Max.) values were calculated based on the number of animals in column 2.

${ }^{3}$ No. of animals for estimating genetic correlations between weight at first insemination and test-day, health, and fertility traits.

In matrix notation, the statistical model [1] for CABW and IBW was

$$
\mathbf{y}=\mathbf{X b}+\mathbf{Z d}+\mathbf{W m}+\mathbf{S p}_{\mathbf{m}}+\mathbf{e}
$$

where $\mathbf{y}$ was a vector of observations for CABW or IBW; $\mathbf{b}$ was a vector of fixed effects including herd, birth year, birth month, and gestation length for $\mathrm{CABW}$, and herd, insemination year, insemination month, and age at first insemination for IBW; $\mathbf{d}$ was a vector of direct additive-genetic effects; $\mathbf{m}$ was a vector of random maternal genetic effects; $\mathbf{p}_{m}$ was a vector of maternal permanent environmental effects; e was a vector of random residual effects; and $\mathbf{X}, \mathbf{Z}, \mathbf{W}$, and $\mathbf{S}$ were incidence matrices for $\mathbf{b}, \mathbf{d}, \mathbf{m}$, and $\mathbf{p}_{\mathbf{m}}$, respectively.
The equations to estimate direct heritabilities $\left(h_{d}^{2}\right)$ maternal heritabilities $\left(h_{m}^{2}\right)$, and total heritabilities $\left(h_{t}^{2}\right)$ were

$$
\begin{gathered}
h_{d}^{2}=\frac{\sigma_{d}^{2}}{\sigma_{d}^{2}+\sigma_{m}^{2}+\sigma_{d m}+\sigma_{p_{m}}^{2}+\sigma_{e}^{2}}, \\
h_{m}^{2}=\frac{\sigma_{m}^{2}}{\sigma_{d}^{2}+\sigma_{m}^{2}+\sigma_{d m}+\sigma_{p_{m}}^{2}+\sigma_{e}^{2}}, \text { and } \\
h_{t}^{2}=\frac{\sigma_{d}^{2}+1.5 \sigma_{d m}+0.5 \sigma_{m}^{2}}{\sigma_{d}^{2}+\sigma_{m}^{2}+\sigma_{d m}+\sigma_{p_{m}}^{2}+\sigma_{e}^{2}},
\end{gathered}
$$

where $\sigma_{d}^{2}$ was the direct genetic variance; $\sigma_{m}^{2}$ was the maternal genetic variance; $\sigma_{d m}$ was the covariance be-

Table 3. Descriptive statistics for incidences of health traits and for success rates (SR) of female fertility traits

\begin{tabular}{lccccc}
\hline & \multicolumn{2}{c}{ Data set $1^{1}$} & & \multicolumn{2}{c}{ Data set $2^{2}$} \\
\cline { 2 - 3 } \cline { 5 - 5 } Trait & No. of animals & SR/incidence (\%) & & No. of animals & SR/incidence (\%) \\
\hline Nonreturn rate after 56 d & 51,947 & 70.06 & & 9,445 & 67.46 \\
Nonreturn rate after 90 d & 51,947 & 65.49 & & 9,445 & 63.43 \\
General disease status & 57,225 & 79.24 & & 9,349 & 78.77 \\
Diarrhea & 57,225 & 5.74 & & 9,349 & 5.77 \\
Respiratory disease & 57,225 & 2.37 & & 9,349 & 4.41 \\
Mastitis & 57,225 & 22.12 & & 9,349 & 23.32 \\
Claw disorders & 57,225 & 27.25 & & 9,349 & 25.20 \\
Female fertility disorders & 57,225 & 41.41 & & 9,349 & 41.53 \\
Metabolic disorders & 57,225 & 1.23 & & 9,349 & 1.51 \\
\hline
\end{tabular}

${ }^{1}$ No. of animals for estimating genetic correlations between calf birth weight and health and fertility traits. ${ }^{2}$ No. of animals for estimating genetic correlations between weight at first insemination and health and fertility traits. 
tween direct and maternal genetic effects; $\sigma_{p_{m}}^{2}$ was the variance for maternal permanent environmental effect; and $\sigma_{e}^{2}$ was the residual variance.

The equation to estimate the genetic correlation $\left(r_{d m}\right)$ between direct additive genetic and maternal genetic effects was

$$
r_{d m}=\frac{\sigma_{d m}}{\sqrt{\sigma_{d}^{2} \times \sigma_{m}^{2}}}
$$

Single Weight Measurement Analysis: Genetic Parameters for Production and Health Traits. A linear animal model (for Gaussian test-day traits), and a threshold model (for binary health traits) was defined for first-lactation test-day production and health traits. The statistical model [2] for both trait categories was

$$
\mathbf{y}=\mathbf{X b}+\mathbf{Z d}+\mathbf{e}
$$

where $\mathbf{y}$ was a vector of observations for test-day production traits (MY1, FP1, FY1, PP1, PY1, MY2, FP2, FY2, PP2, PY2, FPR1, FPR2, SCS1, and SCS2), and of disease liabilities for binary health traits (GDS, DIA, RD, MAST, CL, FF, and MET); $\mathbf{b}$ was a vector of fixed effects including the herd, calving year and calving season; $\mathbf{d}$ was a vector of additive genetic effects; $\mathbf{e}$ was a vector of random residual effects; and $\mathbf{X}$ and $\mathbf{Z}$ were the incidence matrices for $\mathbf{b}$ and $\mathbf{d}$, respectively.

Single Weight Measurement Analysis: Genetic Parameters for Nonreturn Rates. A threshold model [3] including the random service sire effects was defined for NRR56 and NRR90. Model [3] was

$$
\mathbf{y}=\mathbf{X b}+\mathbf{Z d}+\mathbf{W} \mathbf{s}+\mathbf{e},
$$

where $\mathbf{y}$ was a vector of insemination success rates for NRR56 and NRR90; b was a vector of fixed effects including the herd, insemination year, insemination month, and age at first insemination; $\mathbf{s}$ was a vector of random service sire effects; $\mathbf{X}$ and $\mathbf{W}$ were incidence matrices for $\mathbf{b}$ and $\mathbf{s}$, respectively; and $\mathbf{d}$, $\mathbf{e}$, and $\mathbf{Z}$ were the same as defined in model [2].

Single Weight Measurement Analysis: Bivariate Models. A first bivariate model considered CABW and IBW simultaneously. The following covariance structure of random effects was assumed:

$$
\operatorname{Var}\left[\begin{array}{c}
\mathbf{u} \\
\mathbf{m} \\
\mathbf{p}_{\mathbf{m}} \\
\mathbf{e}
\end{array}\right]=\left[\begin{array}{cccc}
\mathbf{G}_{\mathbf{d}} \otimes \mathbf{A} & \mathbf{G}_{\mathbf{d m}} \otimes \mathbf{A} & 0 & 0 \\
\mathbf{G}_{\mathbf{d m}}^{\prime} \otimes \mathbf{A} & \mathbf{G}_{\mathbf{m}} \otimes \mathbf{A} & 0 & 0 \\
0 & 0 & \mathbf{P}_{\mathbf{m}} \otimes \mathbf{I}_{\mathbf{m}} & 0 \\
0 & 0 & 0 & \mathbf{R} \otimes \mathbf{I}_{\mathbf{n}}
\end{array}\right]
$$

where $\mathbf{G}_{\mathbf{d}}$ was a $2 \times 2$ (co)variance matrix for the direct additive genetic effects; $\mathbf{G}_{\mathbf{m}}$ was a $2 \times 2$ (co)variance matrix for the maternal genetic effects; $\mathbf{G}_{\mathrm{dm}}$ was a $2 \times 2$ covariance matrix between direct additive genetic and maternal genetic effects; $\mathbf{A}$ was the additive genetic relationship matrix; $\mathbf{P}_{\mathrm{m}}$ was a $2 \times$ 2 (co)variance matrix for maternal permanent environmental effects; $\mathbf{I}_{\mathbf{m}}$ was an identity matrix for $m$ dams; $\mathbf{R}$ was a $2 \times 2$ (co)variance matrix for residual effects; $\mathbf{I}_{\mathbf{n}}$ was an identity matrix for $n$ observations, and $\otimes$ was the direct matrix product.

In bivariate runs combining model [1] with models $[2]$ and [3], genetic correlations were estimated between CABW or IBW with cow production and health traits, and with nonreturn rates in heifers. The following (co) variance structure of random effects was assumed:

$$
\mathbf{V a r}\left[\begin{array}{c}
\mathbf{u} \\
\mathbf{m} \\
\mathbf{p}_{\mathbf{m}} \\
\mathbf{s} \\
\mathbf{e}
\end{array}\right]=\left[\begin{array}{ccccc}
\mathbf{G}_{\mathbf{d}} \otimes \mathbf{A} & \mathbf{g}_{\mathrm{dm}} \otimes \mathbf{A} & 0 & 0 & 0 \\
\mathbf{g}_{\mathbf{d m}}^{\prime} \otimes \mathbf{A} & \boldsymbol{\sigma}_{\mathbf{m}}^{2} \mathbf{A} & 0 & 0 & 0 \\
0 & 0 & \boldsymbol{\sigma}_{\mathbf{p}_{\mathrm{m}}}^{2} \mathbf{I}_{\mathbf{m}} & 0 & 0 \\
0 & 0 & 0 & \boldsymbol{\sigma}_{\mathrm{s}}^{2} \mathbf{I}_{\mathbf{s}} & 0 \\
0 & 0 & 0 & 0 & \mathbf{R} \otimes \mathbf{I}_{\mathbf{n}}
\end{array}\right]
$$

where $\mathbf{G}_{\mathbf{d}}$ was a $2 \times 2$ (co)variance matrix for the direct additive genetic effects including one production, health, or fertility trait, and CABW or IBW; $\boldsymbol{\sigma}_{\mathrm{m}}^{2}$ was the maternal genetic variance for CABW or IBW; $\mathbf{g}_{\mathrm{dm}}$ was a $2 \times 1$ vector for the covariances between direct additive genetic effects for one weight trait (CABW or IBW) and for one of the production, fertility, or disease traits with maternal genetic effects for CABW or IBW; $\sigma_{\mathrm{p}_{\mathrm{m}}}^{2}$ was the maternal permanent environmental variance for CABW or IBW; $\sigma_{\mathrm{s}}^{2}$ was the variance for service sires; and $\mathbf{I}_{\mathbf{s}}$ was an identity matrix for $s$ service sires (only relevant for NRR56 and NRR90).

For all bivariate models, the BLUPF90 software package (Misztal et al., 2002) was applied. The AIREML algorithm was used for bivariate models with 2 continuous traits. For runs including one binary trait (nonreturn or disease traits), a Bayesian approach and Gibbs sampling was applied. In total, a chain length of 300,000 samples was generated, and the first 60,000 rounds were discarded as "burn-in." Every 10th sample was saved for the calculation of posterior means and standard deviations. Hence, in total, 24,000 samples were the basis to infer genetic parameters. The number of samples and the length of the burn-in period were determined based on visual inspections for genetic covariances, and on the effective sample size. Misztal et al. (2002) suggested an effective sample size of NS = 30 , which was achieved for all runs. 
Repeated Measurement Analysis for Weight Data: Growth Models. To identify the most appropriate function for modeling longitudinal weight data, we evaluated 4 nonlinear growth models using the NLMIXED procedure in SAS University Edition (SAS Institute Inc., Cary, NC). These were the logistic growth model (Fekedulegn et al., 1999), the Gompertz growth model (Wellock et al., 2004), the Brody growth model (Fitzhugh, 1976), and the Richards growth model (Fekedulegn et al., 1999). Additionally, 3 linear models with linear, quadratic, and cubic Legendre polynomials (Kirkpatrick et al., 1990) were analyzed using the MIXED procedure in SAS (SAS Institute Inc.). Evaluation criteria were the Akaike's information criterion (AIC; Akaike, 1973), the Bayesian information criterion (BIC), and residual variances.

Repeated Measurement Analysis for Weight Data: Estimation of Genetic Parameters. An RRM with the time dependent covariate "age in month" was applied to longitudinal BW data. The statistical model [4] was

$$
\mathbf{y}=\mathbf{X b}+\mathbf{Q d}+\mathbf{W m}+\mathbf{Z} \mathbf{p}+\mathbf{S p}_{\mathbf{m}}+\mathbf{e}
$$

where $\mathbf{y}$ was a vector of observations for longitudinal $\mathrm{BW}$; $\mathbf{b}$ was a vector of fixed effects including herdyear-month, and regressions on age in month using cubic Legendre polynomials nested within birth year; d was a vector of direct additive-genetic effects for random regression coefficients, which were modeled with Legendre polynomials of order 3 ; $\mathbf{p}$ was a vector of permanent environmental effects for random regression coefficients, which were modeled with Legendre polynomials of order $3 ; \mathbf{m}$ was a vector of random maternal genetic effects; $\mathbf{p}_{\mathbf{m}}$ was a vector of maternal permanent environmental effects; $\mathbf{e}$ was a vector of random residual effects; and $\mathbf{X}, \mathbf{Q}, \mathbf{W}, \mathbf{Z}$, and $\mathbf{S}$ were incidence matrices for $\mathbf{b}, \mathbf{d}, \mathbf{m}, \mathbf{p}$, and $\mathbf{p}_{\mathbf{m}}$, respectively. Heterogeneous residual variances were assumed across the weighing age for the following time intervals: 0,1 to 4,5 to 8,9 to 12,13 to 16,17 to 20 , and 21 to 24 mo. The following (co)variance structure for random effects was assumed:

$\operatorname{Var}\left[\begin{array}{c}\mathbf{u} \\ \mathbf{m} \\ \mathbf{p} \\ \mathbf{p}_{\mathbf{m}} \\ \mathbf{e}\end{array}\right]=\left[\begin{array}{ccccc}\mathbf{G}_{\mathbf{d}} \otimes \mathbf{A} & \mathbf{g}_{\mathrm{dm}} \otimes \mathbf{A} & 0 & 0 & 0 \\ \mathbf{g}_{\mathbf{d} \mathbf{m}}^{\prime} \otimes \mathbf{A} & \mathbf{g}_{\mathbf{m}} \mathbf{A} & 0 & 0 & 0 \\ 0 & 0 & \mathbf{P} \otimes \mathbf{I}_{\mathbf{p}} & 0 & 0 \\ 0 & 0 & 0 & \sigma_{\mathbf{p}_{\mathbf{m}}}^{2} \mathbf{I}_{\mathbf{m}} & 0 \\ 0 & 0 & 0 & 0 & \mathbf{R} \otimes \mathbf{I}_{\mathbf{n}}\end{array}\right]$,

where $\mathbf{G}_{\mathbf{d}}$ was a $4 \times 4$ (co)variance matrix of random regression coefficients for the direct additive-genetic ef- fects; $\mathbf{g}_{\mathrm{m}}$ was the maternal-genetic variance; $\mathbf{g}_{\mathbf{d m}}$ was the vector of additive genetic covariances between direct and maternal genetic effects; $\mathbf{A}$ was the additive genetic relationship matrix; $\mathbf{P}$ was a $4 \times 4$ (co)variance matrix of random regression coefficients for permanent environmental effects; $\mathbf{I}_{\mathrm{p}}$ was an identity matrix for $\mathrm{p}$ cows; $\sigma_{\mathrm{p}_{\mathrm{m}}}^{2}$ was the variance of random maternal permanent environmental effects; $\mathbf{I}_{\mathrm{m}}$ was an identity matrix for $m$ dams; $\mathbf{R}$ was a (co)variance matrix for residual effects of dimension $7 \times 7$ (for the defined 7 time intervals); $\mathbf{I}_{\mathbf{n}}$ was the identity matrix for $n$ observations, and $\otimes$ was the direct matrix product. Also for the RRM analyses, Gibbs sampling as implemented in BLUP90 (Misztal et al., 2002) was applied, again using a chain length of 300,000 samples, and considering a burn-in period of 60,000 rounds. The thinning interval was set to 10 .

\section{RESULTS AND DISCUSSION}

\section{Genetic Parameters for Single BW Measurements}

Direct, maternal, and total heritabilities for CABW and IBW are given in Table 4 . The direct heritability of 0.47 for CABW was in line with the moderate to high direct heritabilities as reported in previous studies (Table 1), for example, a direct heritability of 0.53 based on weight records from 486 Holstein calves kept in one experimental herd (Coffey et al., 2006). McCorquodale et al. (2013) analyzed weight data from 1,588 Holstein calves. The direct heritability including a recording period from 0 to $8 \mathrm{~d}$ of age was 0.44 . The maternal heritability of 0.19 from our study was larger compared with previous estimates in dairy cattle [e.g., Everett and Magee (1965); Johanson et al. (2011)]. Fisher and Williams (1978) also found a quite large maternal genetic heritability of 0.26 using data from 1,552 Holstein calves. In Nellore beef cattle, heritabilities were 0.32 and 0.10 for direct and maternal effects, respectively (Chud et al., 2014). In the Charolais, Limousin, Blonde d'Aquitaine, and Maine-Anjou breeds, the direct heritabilities ranged from 0.28 to 0.38 , and the corresponding maternal heritabilities were in the range from 0.08 to 0.10 (Phocas and Laloë, 2004). Apparently, in beef as well as in dairy cattle populations, direct heritabilities were significantly larger than the maternal component.

Direct and maternal heritabilities for IBW were significantly smaller compared with estimates for CABW (Table 4). Coffey et al. (2006) also found a decrease of direct BW heritabilities during the time span from birth to weaning age. The genetic part of the total heritability included the direct additive genetic variance for the calves, the maternal genetic variance, and the 
Table 4. Direct $\left(\mathrm{h}_{\mathrm{d}}{ }^{2}\right)$, maternal $\left(\mathrm{h}_{\mathrm{m}}{ }^{2}\right)$, and total $\left(\mathrm{h}_{\mathrm{t}}{ }^{2}\right)$ heritabilities and genetic correlations between direct and maternal genetic effects $\left(\mathrm{r}_{\mathrm{dm}}\right)$ for calf birth weight $(\mathrm{CABW})$ and $\mathrm{BW}$ at first insemination (IBW)

\begin{tabular}{lllllllll}
\hline Weight & $\mathrm{h}_{\mathrm{d}}{ }^{2}$ & $\mathrm{SE}$ & $\mathrm{h}_{\mathrm{m}}{ }^{2}$ & $\mathrm{SE}$ & $\mathrm{h}_{\mathrm{t}}{ }^{2}$ & $\mathrm{SE}$ & $\mathrm{r}_{\mathrm{dm}}$ & $\mathrm{SE}$ \\
\hline CABW & 0.47 & 0.02 & 0.19 & 0.01 & 0.39 & 0.01 & -0.39 & 0.02 \\
IBW & 0.20 & 0.01 & 0.06 & 0.00 & 0.19 & 0.01 & -0.24 & 0.03 \\
\hline
\end{tabular}

covariance between direct and maternal genetic effects. Therefore, given the negative covariance between the 2 genetic sources, the total heritability or realized heritability of mass selection (Willham, 1972) was lower than the direct heritability. The genetic correlation between direct effects of CABW and IBW was 0.31, indicating the changing genetic background of $\mathrm{BW}$ with aging.

The genetic correlations between direct and maternal genetic effects were -0.39 for $\mathrm{CABW}$ and -0.24 for IBW. Accuracy of genetic correlation estimates between direct and maternal genetic effects increases with an increasing number of dams with phenotypes (Heydarpour et al., 2008). In our data set, the 57,868 calves with records for CABW were offspring of 43,714 dams, and the 9,462 heifers with records for IBW were offspring of 8,729 dams. However, only 13,800 dams were phenotyped for CABW, and only 731 dams had records for IBW, indicating 68.43 and $91.62 \%$ of dams with missing BW records, respectively. Heydarpour et al. (2008) recommended a proportion of dams with missing records smaller than $50 \%$, to avoid biased estimates for maternal genetic and maternal permanent environmental variances, and for the direct-maternal covariance component. In consequence, we additionally performed runs based on a reduced data set including only the dams with phenotypes. For this specific data set, the maternal heritability for CABW was 0.22 , and 0.12 for IBW. The direct-maternal genetic correlation was -0.42 for CABW, and -0.26 for IBW. Hence, the results from the analysis as suggested by Heydarpour et al. (2008) confirmed the estimates as presented in Table 4 . The negative genetic correlation between direct and maternal effects was identified in several previous beef cattle analyses, indicating incompatibility between genes increasing an animal's BW and genes contributing to improved maternal performance of a cow (Garrick et al., 1989). Hence, similar genetic or physiological mechanisms seem to exist in dairy cattle. In this regard, Lee (2001) stated that a "biological explanation of genetic antagonism between direct and maternal genetic effects is currently unavailable." From a biological perspective, Bauman and Currie (1980) addressed nutrient competition for either growth or milk yield traits, and Bijma (2006) raised questions addressing genetic modeling aspects. However, also when accounting in statistical models for environmental covariances between dam and offspring records, the antagonistic relationship between direct and maternal effects still existed (Bijma, 2006).

\section{Correlations Between BW and Test-Day Traits}

Genetic and phenotypic correlations between CABW and IBW with test-day traits are given in Table 5. Heritabilities were moderate for production traits, and were low for SCS. The heritabilities for the same trait were identical from 2 runs including either CABW or IBW. In agreement with Mahmoud et al. (2017), heritabilities in same traits were larger at the second official test-day compared with estimates from the first official test-day. Generally, genetic and phenotypic correlations between CABW with productivity and SCS were close to zero. Throughout negative genetic correlations (but also on a very low level) were detected between CABW with FP and with FPR from both test-days. As an indicator for a cow's energy status (Friggens et al., 2007), a high FPR indicates negative energy balance and a quick mobilization of body fat depots. Therefore, the negative genetic correlations between CABW and FPR suggest that animals with large BW early in life tend to prevent energy deficiency early in lactation. However, it is a long time span from the calf toward the milking cow stage. Similarly, only weak associations were identified between the calf health status and milking cow production traits (Mahmoud et al., 2017). The time point for measuring IBW is closer to the lactation stage, and accordingly, a stronger effect of IBW on cow test-day traits was identified (Table 5). The highest genetic correlations were found between IBW with protein yield (i.e., 0.22 with PY1 and 0.24 with PY2). Also, genetic correlations between IBW with MY1 and MY2 were positive, indicating that higher IBW marginally increased milk production at first and second test-days. Close to zero genetic correlations were found between averaged BW records with milk production traits from multiparous Holstein-Friesian cows (Berry et al., 2003a). Veerkamp et al. (2000) correlated BW and production traits from the same lactation, but also from overlapping periods for both trait categories; genetic associations had a minor effect. 
Table 5. Heritabilities for test-day traits, and genetic $\left(\mathrm{r}_{\mathrm{g}}\right)$ and phenotypic $\left(\mathrm{r}_{\mathrm{p}}\right)$ correlations between test-day traits with calf birth weight $(\mathrm{CABW})$ and $\mathrm{BW}$ at first insemination (IBW)

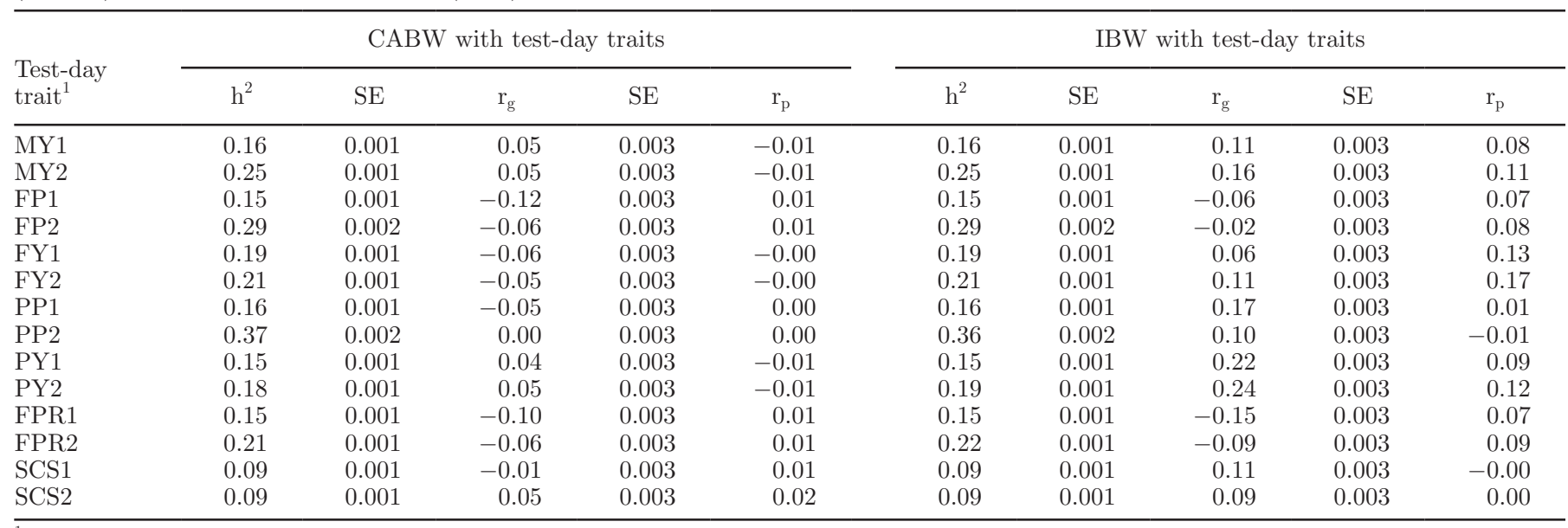

${ }^{1} \mathrm{MY}=$ milk yield; $\mathrm{FP}=$ fat percentage $\mathrm{PP}=$ protein percentage; $\mathrm{FY}=$ fat yield; $\mathrm{PY}=$ protein yield; FPR $=$ fat-to-protein ratio. 1 indicates the observation from the first test-day after calving; 2 indicates the observation from the second test-day after calving.

\section{Correlations Between BW and Nonreturn Rates}

As a female fertility trait, heritabilities for NRR56 and NRR90 were consistently small in all bivariate runs with either CABW or IBW (Table 6). The low heritabilities for nonreturn rates correspond with largescale studies conducted in Holstein cows (Weigel and Rekaya, 2000) or in Norwegian Red (Andersen-Ranberg et al., 2005). As found for the cow test-day traits, small phenotypic correlations were identified between BW measurements and heifer fertility traits (Table 6). Genetic correlations between nonreturn rates with $\mathrm{CABW}$ were slightly negative $(-0.10$ for NR56 and -0.11 for NR90), but positive between nonreturn rates and IBW (0.18; Table 6). Genetically, increasing IBW benefitted nonreturn rates of heifers, indicating the positive associations between improved BW development around insemination time and female fertility. Phenotypic correlations between either CABW or IBW with nonreturn rates were very close to zero (Table 6). Only a limited number of studies focused on associations between BW and nonreturn rates in dairy cattle. Veerkamp et al. (2001) used the BW indicator BCS, and found nega- tive genetic correlations between BCS with the calving interval, and with the time span from calving to first service in first-lactation cows. The genetic correlation between BCS and NRR56 in first lactation was -0.10 (Banos et al., 2004), and -0.11 between BW in the first week after calving and commencement of first luteal activity (Veerkamp et al., 2000). From a management perspective, the "close to zero" phenotypic correlations with female fertility traits suggest an intermediate optimum for BW or BW indicators (e.g., BCS) around insemination time. Genetically, Abdallah and McDaniel (2000) reported that heavier cows from 6 experimental herds conceived earlier than smaller cows.

\section{Correlations Between BW and Health Traits}

Heritabilities for disease traits as well as genetic and phenotypic correlations between health traits with CABW and IBW are shown in Table 7. Heritabilities for health traits are in agreement with estimates from previous studies, that is, with Mahmoud et al. (2017) for cow respiratory diseases, with Harder et al. (2006) for metabolic disorders, with König et al. (2005) or Ger-

Table 6. Posterior means and posterior SD of the Gibbs samples for heritabilities $\left(\mathrm{h}^{2}\right)$ of nonreturn rate after 56 (NRR56) and 90 d (NRR90), and for genetic $\left(r_{g}\right)$ and phenotypic $\left(r_{p}\right)$ correlations between nonreturn rates and calf birth weight $($ CABW) and BW at first insemination (IBW)

\begin{tabular}{|c|c|c|c|c|c|c|c|c|c|c|}
\hline $\begin{array}{l}\text { Heifer fertility } \\
\text { trait }\end{array}$ & \multicolumn{5}{|c|}{ CABW with nonreturn rate } & \multicolumn{5}{|c|}{ IBW with nonreturn rate } \\
\hline NRR56 & 0.03 & 0.01 & -0.10 & 0.08 & -0.01 & 0.02 & 0.01 & 0.18 & 0.17 & -0.03 \\
\hline
\end{tabular}


Table 7. Posterior means and posterior SD of the Gibbs samples for heritabilities $\left(\mathrm{h}^{2}\right)$ of health traits, and for genetic $\left(\mathrm{r}_{\mathrm{g}}\right)$ and phenotypic $\left(\mathrm{r}_{\mathrm{p}}\right)$ correlations between disease traits and calf birth weight $(\mathrm{CABW})$ and $\mathrm{BW}$ at first insemination (IBW)

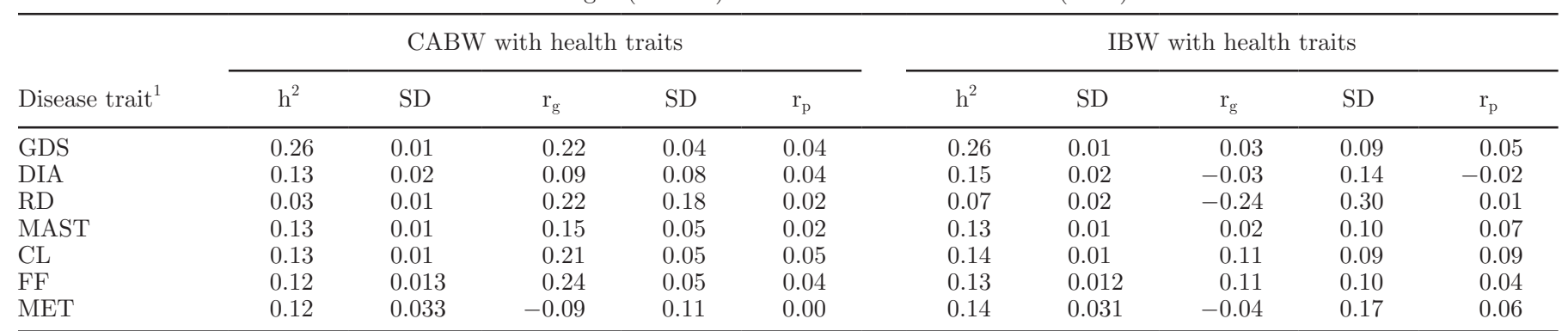

${ }^{1} \mathrm{GDS}=$ general disease status; DIA $=$ diarrhea; $\mathrm{RD}=$ respiratory disease; MAST $=$ mastitis; $\mathrm{CL}=$ claw disorders; FF $=$ female fertility disorders; MET $=$ metabolic disorders.

nand et al. (2012) for claw disorders, and with Zwald et al. (2006) for clinical mastitis. Genetic correlations between CABW and health traits were larger than the corresponding correlations with test-day traits or with nonreturn rates, but also in a narrow range from -0.09 to 0.22 . Genetic correlations were positive and larger than 0.10 between CABW with GDS, MAST, $\mathrm{CL}$, and FF. The positive correlation indicates, from a genetic perspective, that heavier calves have a higher risk for disease occurrence later in life. McCorquodale et al. (2013) stated that calves with higher CABW had less disease early in life, along with improved disease resistance during aging. In contrast, Mahmoud et al. (2017) found improved disease resistance after calving for cows with respiratory and digestive infections during calfhood, independent from growth development. Genetic correlation estimates were even weaker between IBW and cow disease traits. The only obvious difference when comparing CABW and IBW correlations was identified for RD: the genetic correlation between $\mathrm{CABW}$ and $\mathrm{RD}$ was positive $(0.22)$, but negative between IBW and RD (-0.24). Hence, alterations of genetic covariances between BW development and RD suggest deeper analyses in this regard, from a geneticstatistical perspective (e.g., application of RRM), as well as from molecular applications (e.g., studies on gene expressions). The negative correlations between both BW measurements CABW and IBW with MET indicates that animals with more BW or better body development are less susceptible to metabolic disorders (Frigo et al., 2010). Further BW-disease genetic associations were studied in lactating cows. Pérez-Cabal and Charfeddine (2016) reported positive correlations (i.e., antagonistic associations) between BW with sole ulcer, white line disease, and overall definitions of claw disorders. Frigo et al. (2010) found a slightly positive genetic correlation of 0.15 between BW at DIM 10 and mastitis using data from 2 experimental dairy herds.

\section{Genetic Parameters for Longitudinal BW}

The model evaluation criteria AIC, BIC, and residual variances for 4 nonlinear models and Legendre polynomials 1 to 3 orders are compared in Table 8. Based on AIC, the Gompertz growth model gave the best fit. Residual variances and BIC indicated model superiority for Legendre polynomials of third order. Köhn et al. (2007) also suggested modeling of growth curves of the Göttingen minipig using third-order polynomials. Goldberg and Ravagnolo (2015) compared 5 nonlinear models and concluded that the Richards model gave best predictions of weights from birth to maturity for Angus cows kept in pasture-based production systems. Random regression models using cubic Legendre polynomials and cubic regressions were suggested for the description of growth curves in Nellore cattle (Nobre et al., 2003) and in dairy cattle (Brotherstone et al., 2007), respectively.

Due to the results from growth curve evaluation, time-dependent covariates in genetic studies with RRM were modeled using Legendre polynomials of order 3 . Total, direct genetic, and maternal genetic heritabilities for longitudinal BW by age in months are depicted in Figure 1 . The direct and total heritabilities overlapped,

Table 8. Akaike information criterion (AIC), Bayesian information criterion (BIC), and residual variances for longitudinal BW analyses (values in bold represent the lowest value for the respective evaluation criterion)

\begin{tabular}{lrrr}
\hline Model & \multicolumn{1}{c}{ AIC } & \multicolumn{1}{c}{ BIC } & Residual \\
\hline Logistic & 320,503 & 320,536 & 1,157 \\
Gompertz & $\mathbf{3 1 6 , 2 6 9}$ & 316,302 & $\mathbf{1 , 0 1 5}$ \\
Brody & 316,968 & 317,001 & 1,037 \\
Richards & 338,014 & 338,056 & 1,843 \\
Legendre polynomial 1 & 317,531 & 317,537 & 1,055 \\
Legendre polynomial 2 & 316,942 & 316,949 & 1,036 \\
Legendre polynomial 3 & 316,294 & $\mathbf{3 1 6 , 3 0 0}$ & $\mathbf{1 , 0 1 5}$ \\
\hline
\end{tabular}


apart from small differences early in life (0 to $4 \mathrm{mo}$ ). Identical estimates from 5 to 24 mo were due to the extremely small covariance between direct and maternal genetic effects. The direct and total heritabilities were larger than 0.49 at birth, decreased to 0.26 at age mo 1 , and increased gradually to 0.57 at age mo 4 . A gradually increase of direct and total heritabilities was observed between mo 5 and 24, with the largest estimate of 0.83 at the end of the continuous age scale. However, extremely large genetic variances and heritabilities at the peripheries of environmental or time scales were observed in previous RRM applications (Berry et al., 2003b; Strabel et al., 2005), especially in small data sets. Direct BW heritabilities from this study are in agreement with estimates from RRM considering a time span from birth to the age of 33 mo (Brotherstone et al., 2007). Only during the period between 20 to 24 mo, direct heritabilities from our study were significantly larger.

As expected, the maternal heritability for BW gradually decreased from birth to an age of $5 \mathrm{mo}$, and was zero afterward (Nobre et al., 2003). The direct, maternal, and total heritabilities for birth weight estimated from RRM in the present study were $0.58,0.16$, and 0.49 , respectively. The direct heritability was slightly larger than the corresponding heritability estimated from the single-trait animal model for CABW, but the maternal heritability was slightly lower. Insemination age for the heifers ranged from 11 to $26 \mathrm{mo}$, and the direct and total heritabilities during this period were always larger than 0.37 . Those heritabilities were larger than the direct and maternal heritabilities for IBW from the single-trait animal model.

Genetic correlations between BW at birth with BW from remaining age points gradually decreased from 1.00 to 0.12 at an age of 4 mo (Figure 2). Large genetic correlations for neighboring test-days, but a substantial decrease for test-days in greater distance, is well known for longitudinal production records within lactation (e.g., Strabel and Misztal, 1999). The physiological background might be that different genes are "switched on or off" with aging or with DIM. The genetic correlation between BW at birth and at 24 mo was even negative $(-0.20)$. Hence, BW from age points in great distance are genetically different traits. Accordingly, Brotherstone et al. (2007) reported decreasing genetic correlations with an increasing interval between birth and weight date. Genetic correlations between BW from different time points were larger in the study by Coffey et al. (2006). They found a genetic correlation of 0.79 between birth weight and weaning weight in a Holstein-Friesian dairy cattle population. The respective genetic correlation in our study, considering a similar time period, was only 0.20 .

Genetic correlations between direct and maternal genetic effects at the same age were negative throughout

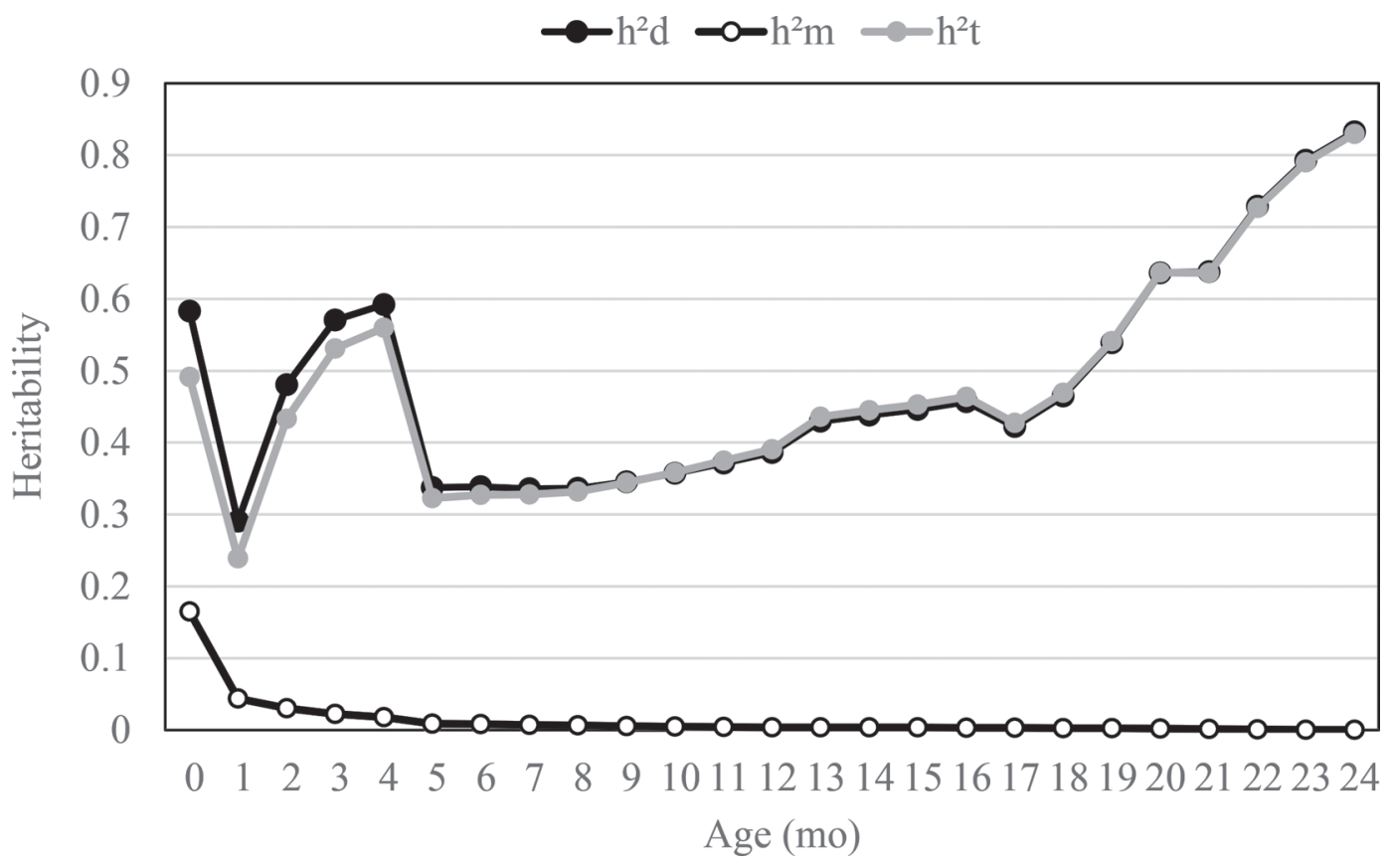

Figure 1. Posterior means of the Gibbs samples for direct $\left(h^{2} d\right)$, maternal $\left(h^{2} m\right)$, and total heritabilities $\left(h^{2} t\right)$ for longitudinal BW. Posterior $\mathrm{SD}$ for direct heritabilities ranged from 0.02 to 0.06 , for maternal heritabilities from 0.00 to 0.04 , and for total heritabilities from 0.01 to 0.04 . 
from birth to the age of $10 \mathrm{mo}$, and from the age of 20 to 24 mo. The correlation coefficient of -0.39 at $\mathrm{d} 0$ was exactly the same value as estimated with an animal model with maternal genetic effects (model 1, results in Table 4). The negative genetic correlations between direct and maternal effects for birth weight were also found in other dairy cattle populations (Hansen et al., 2004; Johanson et al., 2011), as well as in beef cattle (Chud et al., 2014). Boujenane et al. (2015) also stated that those correlations were negative for birth weight, and for BW at 90 and $135 \mathrm{~d}$ in D'man sheep. The direct genetic effect was slightly positive correlated with the maternal genetic effect from mo 11 to 19 . In contrast, a negative correlation of -0.24 was found for IBW and model [1] applications. However, for BW later in life, the maternal genetic component was almost zero, implying that minor changes in covariances can have a major effect on correlation coefficients.

\section{CONCLUSIONS}

As found in beef cattle studies, BW recorded from Holstein dairy calves (trait: $\mathrm{CABW}$ ) and heifers (trait: IBW) had a direct genetic and a maternal genetic component. The direct heritability for CABW estimated from single-trait animal models with maternal genetic effects was 0.47 , and 0.20 for IBW. Comparable direct heritabilities were obtained from RRM for a longitudinal BW data structure. In addition, an antagonistic relationship between direct genetic and maternal genetic effects around birth date was identified, with -0.39 for CABW from single trait as well as repeated measurement analyses. The maternal genetic heritability was 0.19 for CABW, but close to zero later in life, especially in RRM applications. Genetic and phenotypic correlations between CABW or IBW with either cow test-day traits and cow health traits, or with female fertility traits from heifers, were close to zero. However, apart from MET, a general tendency was observed for increasing disease susceptibilities in early lactation for heavier calves.

\section{ACKNOWLEDGMENTS}

The authors gratefully acknowledge funding from the German Federal Ministry of Education and Research $(\mathrm{BMBF})$ and from the Förderverein Bioökonomieforschung e.V. (FBV)/German Holstein Association (DHV) for the collaborative project "KMU-innovativ-10: KuhL-Cow calibration groups for the implementation of selection strategies based on high-density genotyping in dairy cattle," grant no. 031A416C.

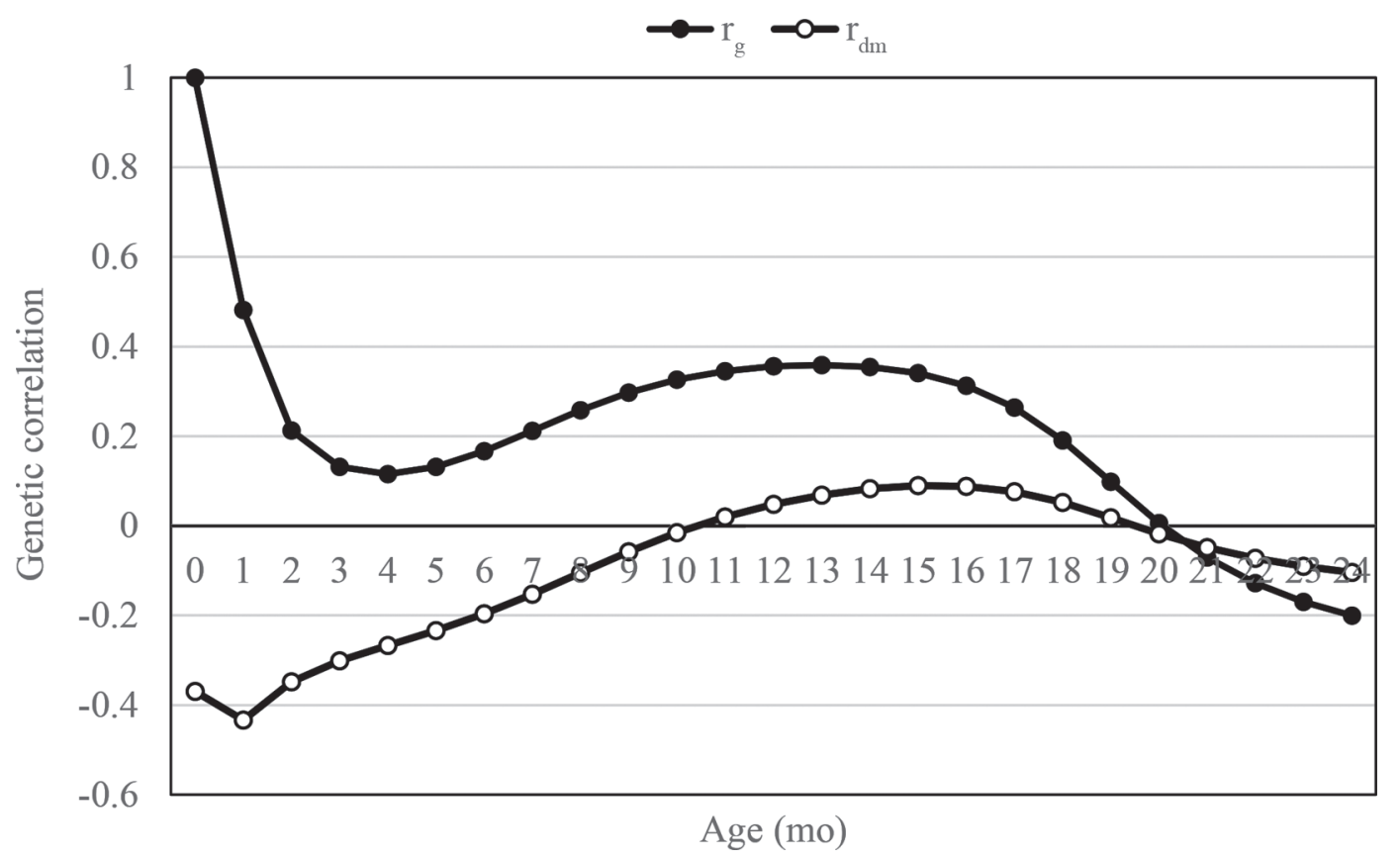

Figure 2. Posterior means of the Gibbs samples for the genetic correlations between calf birth weight and BW from the remaining ages ( $\mathrm{r}_{\mathrm{g}}$ ), and for the correlations between direct and maternal effects across BW ages $\left(\mathrm{r}_{\mathrm{dm}}\right)$. Posterior SD for $\mathrm{r}_{\mathrm{g}}$ ranged from 0.00 to 0.06 , and for $\mathrm{r}_{\mathrm{dm}}$ from 0.09 to 0.12 . 


\section{REFERENCES}

Abdallah, J. M., and B. T. McDaniel. 2000. Genetic parameters and trends of milk, fat, days open, and body weight after calving in North Carolina experimental herds. J. Dairy Sci. 83:1364-1370.

Akaike, H. 1973. Information theory and an extension of the maximum likelihood principle. Pages 267-281 in Second International Symposium on Information Theory. B. N. Petrov and F. Csaki, ed. Academiai Kiado, Budapest, Hungary.

Andersen-Ranberg, I. M., G. Klemetsdal, B. Heringstad, and T. Steine. 2005. Heritabilities, genetic correlations, and genetic change for female fertility and protein yield in Norwegian dairy cattle. J. Dairy Sci. 88:348-355.

Banos, G., S. Brotherstone, and M. P. Coffey. 2004. Evaluation of body condition score measured throughout lactation as an indicator of fertility in dairy cattle. J. Dairy Sci. 87:2669-2676.

Bauman, D. E., and W. B. Currie. 1980. Partitioning of nutrients during pregnancy and lactation: A review of mechanisms involving homeostasis and homeorhesis. J. Dairy Sci. 63:1514-1529.

Berry, D. P., F. Buckley, P. Dillon, R. D. Evans, M. Rath, and R. F. Veerkamp. 2003a. Genetic relationships among body condition score, body weight, milk yield, and fertility in dairy cows. J. Dairy Sci. 86:2193-2204.

Berry, D. P., F. Buckley, P. Dillon, R. D. Evans, M. Rath, and R. F. Veerkamp. 2003b. Genetic parameters for body condition score, body weight, milk yield, and fertility estimated using random regression models. J. Dairy Sci. 86:3704-3717.

Bijma, P. 2006. Estimating maternal genetic effects in livestock. J. Anim. Sci. 84:800-806.

Boujenane, I., A. Chikhib, M. Ibnelbachyrb, and F. Z. Mouha. 2015. Estimation of genetic parameters and maternal effects for body weight at different ages in D'man sheep. Small Rumin. Res. 130:27-35.

Brotherstone, S., M. P. Coffey, and G. Banos. 2007. Genetic parameters of growth in dairy cattle and associations between growth and health traits. J. Dairy Sci. 90:444-450.

Byrne, T. J., B. F. S. Santos, P. R. Amer, D. Martin-Collado, J. E. Pryce, and M. Axford. 2016. New breeding objectives and selection indices for the Australian dairy industry. J. Dairy Sci. 99:81468167.

Chud, T. C. S., S. L. Caetano, M. E. Buzanskas, D. A. Grossi, D. G. F. Guidolin, G. B. Nascimento, J. O. Rosa, R. B. Lôbo, and D. P. Munari. 2014. Genetic analysis for gestation length, birth weight, weaning weight, and accumulated productivity in Nellore beef cattle. Livest. Sci. 170:16-21.

Coffey, M. P., J. Hickey, and S. Brotherstone. 2006. Genetic aspects of growth of Holstein-Friesian dairy cows from birth to maturity. J. Dairy Sci. 89:322-329.

Coffey, M. P., G. Simm, and S. Brotherstone. 2002. Energy balance profiles for the first three lactations of dairy cows estimated using random regression. J. Dairy Sci. 85:2669-2678.

Collard, B. L., P. J. Boettcher, J. C. M. Dekkers, D. Petitclerc, and L. R. Schaeffer. 2000. Relationships between energy balance and health traits of dairy cattle in early lactation. J. Dairy Sci. 83:2683-2690.

Everett, R. W., and W. T. Magee. 1965. Maternal ability and genetic ability of birth weight and gestation length. J. Dairy Sci. 48:957-961.

Fekedulegn, D., M. Mac Siurtain, and J. Colbert. 1999. Parameter estimation of nonlinear growth models in forestry. Silva Fenn. 33:327-336.

Fisher, L. J., and C. J. Williams. 1978. Effect of environmental factors and fetal and maternal genotype on gestation length and birth weight of Holstein calves. J. Dairy Sci. 61:1462-1467.

Fitzhugh, H. A. Jr. 1976. Analysis of growth curves and strategies for altering their shape. J. Anim. Sci. 42:1036-1051.

Fox, J., and S. Weisberg. 2011. An R Companion to Applied Regression, Second Edition. Sage, Thousand Oaks, CA. Accessed Jan. 19, 2017. http://socserv.socsci.mcmaster.ca/jfox/Books/Companion.
Friggens, N. C., C. Ridder, and P. Lovendahl. 2007. On the use of milk composition measures to predict energy balance in dairy cows. J. Dairy Sci. 90:5453-5467.

Frigo, E., C. D. Dechow, O. Pedron, and B. G. Cassell. 2010. The genetic relationship of body weight and early-lactation health disorders in two experimental herds. J. Dairy Sci. 93:1184-1192.

Garrick, D. J., E. J. Pollak, R. L. Quaas, and L. D. Van Vleck. 1989. Variance heterogeneity in direct and maternal weight traits by sex and percent purebred for Simmental-sired calves. J. Anim. Sci. 67:2515-2528.

Gernand, E., P. Rehbein, U. U. von Borstel, and S. König. 2012. Incidences of and genetic parameters for mastitis, claw disorders, and common health traits recorded in dairy cattle contract herds. J. Dairy Sci. 95:2144-2156.

Goldberg, V., and O. Ravagnolo. 2015. Description of the growth curve for Angus pasture-fed cows under extensive systems. J. Anim. Sci. 93:4285-4290.

Hansen, M., M. S. Lund, J. Pedersen, and L. G. Christensen. 2004. Gestation length in Danish Holsteins has weak genetic associations with stillbirth, calving difficulty, and calf size. Livest. Prod. Sci. 91:23-33.

Harder, B., J. Bennewitz, D. Hinrichs, and E. Kalm. 2006. Genetic parameters for health traits and their relationship to different persistency traits in German Holstein dairy cattle. J. Dairy Sci. 89:3202-3212.

Heydarpour, M., L. R. Schaeffer, and M. H. Yazdi. 2008. Influence of population structure on estimates of direct and maternal parameters. J. Anim. Breed. Genet. 125:89-99.

Johanson, J. M., P. J. Berger, S. Tsuruta, and I. Misztal. 2011. A Bayesian threshold-linear model evaluation of perinatal mortality, dystocia, birth weight, and gestation length in a Holstein herd. J. Dairy Sci. 94:450-460

Kirkpatrick, M., D. Lofsvold, and M. Bulmer. 1990. Analysis of the inheritance, selection and evolution of growth trajectories. Genetics 124:979-993.

Köhn, F., A. R. Sharifi, and H. Simianer. 2007. Modeling the growth of the Goettingen minipig. J. Anim. Sci. 85:84-92.

König, S., A. R. Sharifi, H. Wentrot, D. Landmann, M. Eise, and H. Simianer. 2005. Genetic parameters of claw and foot disorders estimated with logistic models. J. Dairy Sci. 88:3316-3325.

Lamb, R. C., and B. O. Barker. 1975. Genetic relationship between birth weight and adult weight in Holsteins. J. Dairy Sci. 58:724728

Lassen, J., and P. Løvendahl. 2016. Heritability estimates for enteric methane emissions from Holstein cattle measured using noninvasive methods. J. Dairy Sci. 99:1959-1967.

Lee, C. 2001. On the negative estimates of direct and maternal genetic correlation-A review. Asian-australas. J. Anim. Sci. 15:1222-1226.

Mahmoud, M., T. Yin, K. Brügemann, and S. König. 2017. Phenotypic, genetic, and single nucleotide polymorphism marker associations between calf diseases and subsequent performance and disease occurrences of first-lactation German Holstein cows. J. Dairy Sci. 100:2017-2031.

McCorquodale, C. E., A. Sewalem, F. Miglior, D. Kelton, A. Robinson, A. Koeck, and K. E. Leslie. 2013. Short communication: Analysis of health and survival in a population of Ontario Holstein heifer calves. J. Dairy Sci. 96:1880-1885.

Misztal, I., S. Tsuruta, T. Strabel, B. Auvray, T. Druet, and D. H. Lee. 2002. BLUPF90 and related programs (BGF90): Proc. 7th World Congr. Genet. Appl. Livest. Prod. Montpellier, France. Communication No. 28-07.

Nobre, P. R. C., I. Misztal, S. Tsuruta, J. K. Bertrand, L. O. C. Silva, and P. S. Lopes. 2003. Analyses of growth curves of Nellore cattle by multiple-trait and random regression models. J. Anim. Sci. 81:918-926.

Pérez-Cabal, M. A., and N. Charfeddine. 2016. Short communication: Association of foot and leg conformation and body weight with claw disorders in Spanish Holstein cows. J. Dairy Sci. 99:91049108 . 
Phocas, F., and D. Laloë. 2004. Genetic parameters for birth and weaning traits in French specialized beef cattle breeds. Livest. Prod. Sci. 89:121-128.

Stock, K. F., J. Cole, J. Pryce, N. Gengler, A. Bradley, L. Andrews, B. Heringstad, and C. Egger-Danner. 2013. Standardization of health data-ICAR guidelines including health key. ICAR Tech. Ser. 17:75-81.

Strabel, T., and I. Misztal. 1999. Genetic parameters for first and second lactation milk yields of Polish Black and White cattle with random regression test-day models. J. Dairy Sci. 82:2805-2810.

Strabel, T., J. Szyda, E. Ptak, and J. Jamrozik. 2005. Comparison of random regression test-day models for Polish Black and White cattle. J. Dairy Sci. 88:3688-3699.

Thompson, R., and K. Meyer. 1986. A review of theoretical aspects in the estimation of breeding values for multi-trait selection. Livest. Prod. Sci. 15:299-313.

Veerkamp, R. F., E. P. C. Koenen, and G. De Jong. 2001. Genetic correlations among body condition Score, yield, and fertility in first-parity cows estimated by random regression models. J. Dairy Sci. 84:2327-2335.
Veerkamp, R. F., J. K. Oldenbroek, H. J. Van Der Gaast, and J. H. J. Van Der Werf. 2000. Genetic correlation between days until start of luteal activity and milk yield, energy balance, and live weights. J. Dairy Sci. 83:577-583.

Veerkamp, R. F., and R. Thompson. 1999. A covariance function for feed intake, live weight, and milk yield estimated using a random regression model. J. Dairy Sci. 82:1565-1573.

Weigel, K. A., and R. Rekaya. 2000. Genetic parameters for reproductive traits of Holstein cattle in California and Minnesota. J. Dairy Sci. 83:1072-1080.

Wellock, I. J., G. C. Emmans, and I. Kyriazakis. 2004. Describing and predicting potential growth in the pig. Anim. Sci. 78:379-388.

Willham, R. L. 1972. The role of maternal effects in animal breeding III. Biometrical aspects of maternal effects in animal. J. Anim. Sci. 35:1288-1293.

Zwald, N. R., K. A. Weigel, Y. M. Chang, R. D. Welper, and J. S. Clay. 2006. Genetic analysis of clinical mastitis data from onfarm management software using threshold models. J. Dairy Sci. 89:330-336. 